\title{
Spatially-Resolved EELS Analysis of Surface Chemistry of Metallic Lithium for the Development of Li-Air Battery.
}

\author{
M.L. Trudeau ${ }^{1}$, R. Veillette ${ }^{1}$, P. Bouchard ${ }^{2}$ and K. Zaghib ${ }^{2}$ \\ ${ }^{1}$ Materials Science, Hydro-Québec Research Institute, 1800 Boul. Lionel-Boulet, Varennes, Québec, \\ Canada, J3X 1S1 \\ ${ }^{2}$ Energy Storage and Conversion, Hydro-Québec Research Institute, 1800 Boul. Lionel-Boulet, \\ Varennes, Québec, Canada, J3X 1S1
}

Li-air battery is considered one of the most desired technologies for electric vehicles because of its high theoretical specific energy (more than $3500 \mathrm{Wh} \mathrm{kg}^{-1}$, including oxygen), which could enable a driving distance of $>500 \mathrm{~km}$ [1]. However, there are many technical challenges that hinder the practical use of lithium-air batteries. To address these technical challenges, significant research has been dedicated in the last 5 years on investigations of electrolytes, electrode materials and structures, catalysts, binders and anodes [1]. Despite progress in understanding the mechanisms associated with the electrode reactions, the current lithium-air technology is far from the requirements for use in electric vehicles, especially with respect to the cycle life and the power capability [1].

The further development of Li-air battery will necessitate a better understanding of the microstructure and chemical nature of Li metallic sheet. Metallic lithium is highly sensitive to hydrogen, oxygen, nitrogen, and carbon dioxide, which are the major components of wet air, and is more likely to form rapidly $\mathrm{LiOH}, \mathrm{Li}_{2} \mathrm{O}, \mathrm{Li}_{2} \mathrm{O}_{2}, \mathrm{Li}_{3} \mathrm{~N}$, and $\mathrm{Li}_{2} \mathrm{CO}_{3}$ species $[2,3]$ when exposed to air and/or moisture. Figure-1a shows XPS Li1s spectra acquired by depth-profiling through the different surface layers found on a pure metallic Li sheet while Figure-1b gives a representation of these different layers with typical thicknesses.

Because of this very high surface reactivity and the low hardness of $\mathrm{Li}$, it is thus very difficult to prepare thin sample from a specific Li sheet for direct TEM observations and chemical analysis of the material structure and surface chemical nature. In this work we present a first direct SR-TEMEELS study of the surface chemical nature of Li sheets. We have used a Hitachi air-protection cryogenic FIB holder to prepare thin Li samples and study the surface chemistry using SpatiallyResolved EELS (SR-EELS). The thin samples were prepared from different Li sheets using FIB (NB5000 from Hitachi) with the sample temperature at $\sim-90{ }^{\circ} \mathrm{C}$. Figure-1c shows a typical FIB sample that was obtained. The samples were transferred under vacuum using the same holder into a Hitachi HF-3300 cold FEG E-TEM for EELS analysis at low temperature without air contact.

Spatially-resolved EELS was done using a high resolution GIF system (Gatan Quantum ER). Figuire-2a shows a TEM image selected with the rectangular slit while Figure-2b), c) and d) show the spectrum images for the $\mathrm{Li}_{-\mathrm{K} \text {-edge }}, \mathrm{O}_{\text {-K-edge }}$ and $\mathrm{C}_{\text {-K-edge }}$ respectively. Figure-3a) presents again a $\mathrm{Li}_{\text {-K-edge }}$ spectrum image while Figure-3b) shows four extracted spectrum taken at different positions on the sample. One can see the clear the change in the Li-K-edge as a function of the depth from the surface (\#1) to the last one (\#4) that is representative of metallic Li.

[1] M.H. Cho, J. Trottier, C. Gagnon, P. Hovington, D. Clément, A. Vijh, C.-S. Kim, A. Guerfi, R. Black, L. Nazar and K. Zaghib, J. Power Source 268, 565-574 (2014)

[2] N. Brodusch, K. Zaghib and R. Gauvin, Micros. Res. \& Tech. 78, 30-39 (2015) 
[3] D. Jeppson, J. Ballif, W. Yuan and B. Chou, 1978. Lithium literature review: Lithium's properties and interactions. Richland, Washington: Hanford Engineering Development Lab.

[4] The authors would like to thank the assistance of the staff at Hitachi High Technologies for some samples observation.

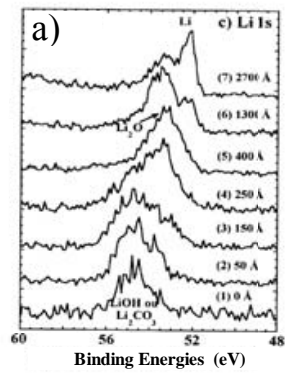

\begin{tabular}{|c|c|}
\hline b) & C-(C,H) $50 \AA$ \\
\hline & $\begin{array}{c}\mathrm{Li}_{2} \mathrm{CO}_{2} \text { et } \mathrm{LiOH} \\
\sim 200 \AA\end{array}$ \\
\hline & $\mathrm{Li}_{2} \mathrm{O}+(\mathrm{L}-\mathrm{C})$ \\
\hline & $>2450 \AA$ \\
\hline & $\mathrm{Li}$ \\
\hline
\end{tabular}

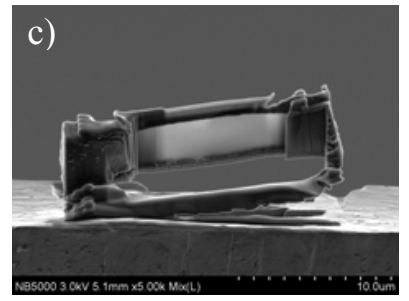

Figure 1. a) XPS spectra as a function of depth for a typical metallic Li sheet; b) A representation of the typical chemical species (passivation layers) at the surface of a metallic Li sheet; c) example of a Li sample taken from such a Li metallic sheet through cryo-fibbing.
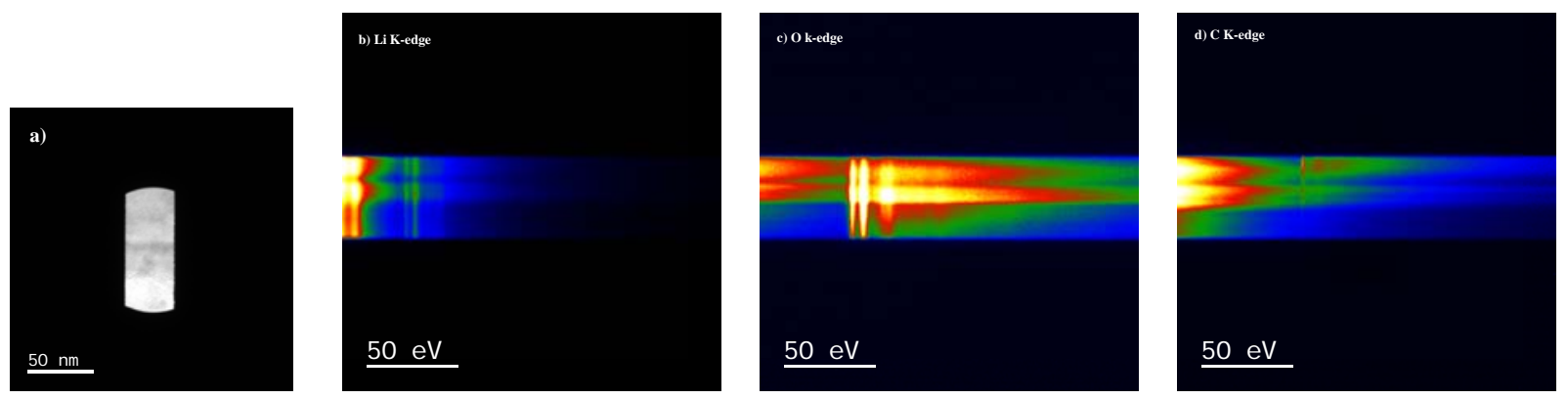

Figure 2. SR-TEM-EELS images for a Li FIB samples. a) TEM image selected with the rectangular slit; b) Spectrum image for the Li K-edge; c) Spectrum image for the O K-edge and d) Spectrum image for the $\mathrm{C} \mathrm{K}$-edge
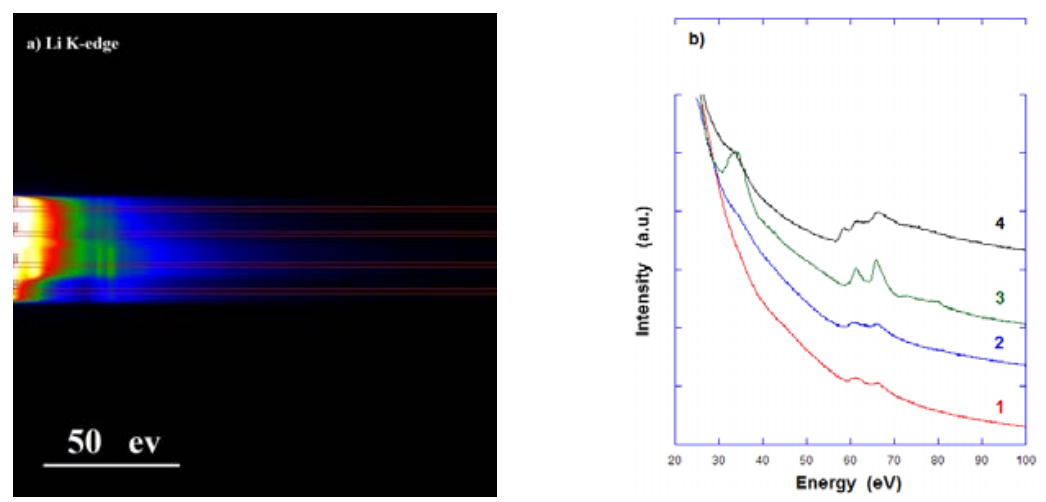

Figure 3. a) SR-TEM-EELS images for a Li FIB sample with b) 4 EELS spectrum taken at different position/depth (from the near the surface at the top (\#1) to the bottom (\#4)). Spectra \#4 is representative of metallic Li. 